This item was submitted to Loughborough's Research Repository by the author.

Items in Figshare are protected by copyright, with all rights reserved, unless otherwise indicated.

\title{
Influence of carrying heavy loads on soldiers' posture, movements and gait
}

PLEASE CITE THE PUBLISHED VERSION

http://dx.doi.org/10.1080/00140130600757237

\section{PUBLISHER}

(C) Taylor \& Francis Ltd

\section{VERSION}

AM (Accepted Manuscript)

\section{PUBLISHER STATEMENT}

This work is made available according to the conditions of the Creative Commons Attribution-NonCommercialNoDerivatives 4.0 International (CC BY-NC-ND 4.0) licence. Full details of this licence are available at: https://creativecommons.org/licenses/by-nc-nd/4.0/

\section{LICENCE}

CC BY-NC-ND 4.0

\section{REPOSITORY RECORD}

Attwells, Renee L., Stewart A. Birrell, Robin H. Hooper, and Neil J. Mansfield. 2019. "Influence of Carrying Heavy Loads on Soldiers' Posture, Movements and Gait”. figshare. https://hdl.handle.net/2134/17047. 


\title{
INFLUENCE OF CARRYING HEAVY LOADS ON SOLDIERS'
} POSTURE, MOVEMENTS AND GAIT

\author{
Department of Human Sciences \\ Loughborough University \\ Leicestershire UK \\ LE11 3TU
}

Authors:

Miss Renee.L.Attwells

$\mathrm{PhD}$ Candidate

Department of Human Sciences

Loughborough University

Leicestershire UK

LE11 3TU

rattwells@yahoo.com.au

Phone: +44 (0) 1509228483

Fax: +44 (0) 1509223940

Mr Stewart.A.Birrell

- $\quad$ PhD Candidate

Department of Human Sciences

Loughborough University

Leicestershire UK

LE11 3TU

Dr Robin.H.Hooper

Lecturer

Department of Human Sciences

Loughborough University

Leicestershire UK

LE11 3TU

Dr Neil.J.Mansfield

Senior Lecturer

Department of Human Sciences

Loughborough University

Leicestershire UK

LE11 3TU

Word Count: 2,984 including references in text 


\begin{abstract}
Military personnel are required to carry heavy loads whilst marching; this load carriage representing a substantial component of training and combat. Studies in the literature mainly concentrate on physiological effects, with few biomechanical studies of military load carriage systems (LCS). This study examines changes in gait and posture caused by increasing load carriage in military LCS. The 4 conditions used during this study were: control (including rifle, boots and helmet carriage, totalling 8 kg), webbing (weighing $8 \mathrm{~kg}$ ), backpack (24 kg) and a Light Antitank Weapon (LAW, $10 \mathrm{~kg}$ ), resulting in an incremental increase in load carried from 8, 16, 40 to $50 \mathrm{~kg}$. Twenty male soldiers were evaluated in the saggital plane using a 3-dimensional CODA $^{\mathrm{TM}}$ motion analysis system. Measurements of ankle, knee, femur, trunk and craniovertebral angles and spatiotemporal parameters were made during self-paced walking. Results showed spatiotemporal changes were unrelated to angular changes, perhaps a consequence of military training. Knee and femur ranges of motion (control, $21.1^{\circ} \pm 3.0$ and $33.9^{\circ} \pm 7.1$ respectively) increased $(\mathrm{p}<0.05)$ with load (LAW, $25.5^{\circ} \pm 2.3$ and $37.8^{\circ} \pm 1.5$ respectively). The trunk flexed significantly further forward confirming results from previous studies. In addition, the craniovertebral angle decreased $(\mathrm{p}<0.001)$ indicating a more forward position of the head with load. It is concluded that the head functions in concert with the trunk to counterbalance load. The higher muscular tensions necessary to sustain these changes have been associated with injury, muscle strain and joint problems.
\end{abstract}

\title{
KEYWORDS
}

Posture, Load carriage, Military, Gait 


\section{Introduction}

The backpack (or rucksack) is one of several available forms of manual load carriage that is often used by schoolchildren, backpackers and the military. It is seen as an appropriate way to load the body close to the centre of gravity, while maintaining stability (Chansirinukor et al. 2001). In particular, marching whilst carrying loads is a substantial component of military training and combat, the loads frequently representing a large percentage of a soldier's bodyweight (BW). There is also a tendency for load to increase as advancements in technology require soldiers to carry more equipment (Knapik et al. 1996).

Several reviews of load carriage have concluded that possible determinants of load carriage ability include age, anthropometry, strength, training, body composition and gender (Haisman 1988, Knapik, et al. 1996). Other relevant determinants include placement and dimensions of the load, biomechanical factors, climate, terrain and gradient.

Physiological aspects of load carriage have been a focus of previous research (Datta and Ramanathan 1971, Martin and Nelson 1986, Kirk and Schneider 1992, Bhambhani et al. 1997, Harman et al. 1997, Harman et al. 1999, Vacheron et al. 1999a), Lloyd and Cooke 2000a, Quesada et al. 2000). These studies have predominantly concentrated on the effect of load carriage on energy cost, but have also examined the effects of speed and training.

This study considers the biomechanical effects loads have on the human body. In particular, changes in posture and gait mechanics of military personnel whilst carrying loads could have implications for future design of equipment. Studies have been conducted on backpackers (Ghori and Luckwill 1985, Bloom and WoodhullMcNeal 1987, Cook and Neumann 1987, Lloyd and Cooke 2000b), military personnel, (Martin and Nelson 1985, Martin and Nelson 1986, Knapik, et al. 1991, Holewijn and Lotens 1992, Harman et al. 1994, Johnson et al. 1995, Knapik, et al. 1997, Tilbury-Davis and Hooper 1999, Harman et al. 2000a), and school children (Pascoe et al. 1997, Chansirinukor et al. 2001, Merati et al. 2001, Wang et al. 2001, Whittfield et al. 2001, Chow et al. 2005). These investigations have included the analysis of EMG, kinematic and kinetic data. 
One mechanical effect of load carriage inevitably observed is an increased forward lean when carrying loads on the back. Martin and Nelson (1986) examined the effect of five different military loads $(0.8 \mathrm{~kg}, 9.5 \mathrm{~kg}, 17.7 \mathrm{~kg}, 30.0 \mathrm{~kg}$ and 36.8 $\mathrm{kg}$ ). Little change was seen until a backpack (weighing $36.8 \mathrm{~kg}$ ) was carried. Head on trunk position has only been measured in studies on children (Pascoe et al. 1997, Chansirinukor et al. 2001, Hong and Cheung 2003), with relatively small loads increasing the forward position of the head.

The aims of this study were to measure the changes in posture and gait caused by carrying a variety of military loads and to study the extent and nature of these changes.

\section{Methods}

\subsection{Participants}

Twenty male soldiers (age $20.2 \pm 2.4 \mathrm{yr}$, mean \pm s.d.) were recruited, screened for exclusion criteria and declared fit for duty by their superiors. After consent was obtained, anthropometric data were recorded: stature $176.4 \pm 6.5 \mathrm{~cm}$, weight $74.9 \pm$ $11.0 \mathrm{~kg}$ and outside leg length $89.7 \pm 4.2 \mathrm{~cm}$.

\section{$2.2 \quad$ Experimental procedure}

The protocol was approved by the local ethical committee. A CODA ${ }^{\mathrm{TM}} \mathrm{mpx} 30$ motion analysis system was used. Seventeen active markers (infra-red LEDs) were placed on the right-hand side of the body. These identified segments of the lower limb, trunk, head and backpack in real-time throughout stance phase. A virtual marker was used to represent the greater trochanter, as the actual marker was obscured from view during the 3 loading conditions. The control condition verified that the difference between the virtual and actual femur angles was a mean of $2.1 \%$ in the $\mathrm{x}-\mathrm{z}$ plane during stance phase. Marker positions were sampled at $200 \mathrm{~Hz}$, with only sagittal plane kinematic data being analysed.

The replication of normal load carriage situations that military personnel encounter on a daily basis was of importance. The UK Army standard issue 90 Pattern (PLCE) Belt Webbing and Bergen (backpack) were used. Participants also wore standard issue boots, helmet and carried an unloaded SA80 rifle in all testing conditions (figure 1). 
[Insert figure 1 here]

Participants walked at a self-selected speed. A sufficient distance $(5 \mathrm{~m})$ at either end of the testing area ensured that natural gait patterns were collected. Once 5 successful trials were complete the participant proceeded to the next condition. Conditions were always completed in the same order (figure 1), as it was not pragmatic to randomize order due to equipment and marker additions in subsequent conditions. This was not ideal as fatigue effects may have influenced the gait and posture adopted by participants. However, these potential effects were considered minimal as the periods of load carriage were short (approximately 10 minutes) for each condition with adequate rest periods before the next condition.

\subsection{Data reduction and smoothing}

The angles shown in figure 2 were calculated and are presented from -20 to $120 \%$ of stance phase, so ensuring any anomalies around heel strike $(0 \%)$ and toe-off (100\%) may be observed. Despite action being taken to minimize marker dropout, trials were removed when equipment failure or marker dropout distorted results. Mean data from the 5 repeat trials was calculated for each participant. To obtain a single representation of these data, the means and 95\% confidence intervals for each condition were calculated for all 20 participants.

\section{$2.4 \quad$ Statistics}

A one-way ANOVA (within subjects) with repeated measures was performed on all spatiotemporal parameters and on maximum, minimum, range of motion (ROM) and mean values for all angular data. For the significant main effect pair-wise comparisons with Bonferroni correction were used. A Kolmogorov-Smirnov test was also completed to determine distribution of participant characteristics, with normal population achieved in terms of height and weight.

[Insert figure 2 here] 


\section{Results}

\subsection{Spatiotemporal parameters}

Stride length was observed to increase between the control and webbing condition (table 1), but decreased whilst undertaking the backpack condition compared to the webbing. Finally, a further decrease was seen in the LAW condition, bringing stride lengths back in line with the control. Stride frequency followed similar patterns, while stance time trends displayed the inverse effects to compensate (table 1).

[Insert table 1 here]

The ANOVA revealed significant changes for all four spatiotemporal parameters. However these differences were inconsistent over the four conditions. Results showed a significantly greater speed in the webbing condition $(1.56 \mathrm{~m} / \mathrm{s})$ compared to the control $(1.42 \mathrm{~m} / \mathrm{s} ; \mathrm{p}<0.001)$. Consequentially, there were significant differences in the other three parameters between these two conditions (all at significance level $\mathrm{p}<0.01)$. Differences between the webbing and backpack conditions were only seen with stance time and speed $(\mathrm{p}<0.01)$, and similarly with the backpack and LAW conditions. The webbing condition produced significantly greater speeds and shorter stance times than all the other conditions, $(\mathrm{p}<0.01)$.

\subsection{Angular data}

\subsubsection{Lower limb}

[Insert figure 3 here]

The ankle showed a trend (although not significant, $\mathrm{p}>0.05$ ) for an increase in the maximum angle when load was added (figure 3). This maximum occurred at around $85 \%$ of stance time, occurring just before toe-off where the ankle is in a more extended position with additional load. Due to this a trend was also seen with ankle $\operatorname{ROM}(\mathrm{p}=0.068)$.

As load was added the ROM at the knee increased (figure 4a). Significant differences were observed between the control and backpack and LAW conditions $(p<0.005)$, the same trend being seen with the addition of webbing. ROM at the knee increased from $21.1^{\circ} \pm 3.0$ in the control condition to $25.5^{\circ} \pm 2.3$ with the backpack. 
The ROM increase at the knee is due to increased flexion at heel strike and during the loading response phase (0-25\% stance time), and greater extension at the beginning of toe-off (approximately 80\%).

The femur angle also increased with load (figure $4 \mathrm{~b}$ ). There was a significant difference between control and webbing conditions $(\mathrm{p}<0.001)$. The backpack and LAW conditions are both significantly different from the control and webbing conditions $(\mathrm{p}<0.001)$, but not from one another. Also, the addition of any load significantly increased the maximum femur angle $(\mathrm{p}<0.001)$. Femur ROM increased due to increased flexion of the hip at heel strike (or a higher knee lift), and greater extension during the toe-off phase, the knee being further away from the mid-line of the body.

[Insert figure 4 here]

\subsubsection{Upper body}

The trunk and craniovertebral angles also showed significant changes with the addition of load (figure 5). The trunk angle showed no change in ROM or in the distribution of the data. To counter-balance the effect of load, the participant leant further forward $(\mathrm{p}<0.005)$ as indicated by decreasing values of trunk angle, becoming negative forward of vertical (figure 2). During the control condition the mean trunk angle for the stance phase was $4.8^{\circ} \pm 1.9$, decreasing to $-13.0^{\circ} \pm 2.7$ with the LAW.

The craniovertebral angle showed similar patterns to the trunk angle with no significant change in the ROM or data distribution, but changes to the mean values were observed (figure 5). No significant changes were observed between the control and webbing conditions ( $\mathrm{p}>0.05$ ), but adding a backpack and then a LAW had the effect of significantly decreasing this angle $(\mathrm{p}<0.001)$ indicating a more forward head posture.

[Insert figure 5 here]

\section{Discussion}

\subsection{Spatiotemporal parameters}

As walking speed was participant selected, variation was expected. The higher mean speed observed in the webbing condition was unexpected. A change in speed results in consequential changes in stride length and stride frequency. This in turn can 
alter the ROM of angles such as those at the ankle and hip (Harman et al. 2000b). However, knee or trunk angle changes were unrelated to changes of speed.

As load increases stride length normally decreases, increasing the period of double support, so providing greater stability. This, however, is only seen at fixed pace. With self-selected pacing such observations have not been as clear (Harman et al. 1992, Charteris 1998). This is supported by present results, as differences were only seen with the addition of webbing. This suggests little can be concluded from the faster speed in the webbing condition; it may be artefactual, perhaps a consequence of military training, or of the fixed order of conditions.

Conclusions from these data are limited as just one CODA ${ }^{\mathrm{TM}}$ sensor unit was used. Double support and swing time measurements were not possible. In fact, only 2$\mathrm{D}$, saggital plane data were analysed as military equipment obscured markers and because of the low variability of gait patterns in this plane (Kadaba et al. 1989). It has also been suggested that the change in stride length and stride frequency could result from a decrease in pelvic rotation when load is carried (LaFiandra et al. 2003). It is interesting to speculate whether (military) training, especially the use of set pacing, would cause differing responses compared to civilian participants.

\subsection{Angular data}

\subsubsection{Lower limb}

As mentioned above, changes in ankle ROM can occur as speed changes (Harman et al. 2000b). Also, changes in the flexion and extension of the ankle may be affected by the addition of load. Trends for changes in the ankle angle were only observed in this study when comparing control to LAW conditions. Kinoshita (1985) suggests this is due to increased dorsiflexion of the foot that facilitates greater knee flexion, ultimately absorbing the impact forces at heel strike.

Load might be expected to increase both the flexion and extension that occurs at the knee, simply because of the need to transport a greater mass and the associated increased energy requirement. Also, increased knee flexion at heel strike is seen as a protective measure to help absorb impact forces. In the present study there is a significant increase in the ROM as load is increased compared to the control condition (figure 4a). This response to load has been found by several researchers (e.g. Kinoshita, 1985 and Harman et al. 2000a). The latter showed greater flexion at heel 
strike and extension at toe-off, resulting in significant increases in knee ROM, as load increased.

ROM of the femur angle was significantly different between all conditions apart from backpack to LAW, increasing with load. Harman et al. (2000a) noted that there was an increase in the degree of hip motion as increased load was applied. They suggest that the increased forward lean of the trunk accounted for this change. The angle measured in their study was relative to the trunk, whereas these data are relative to the horizontal and therefore remove the effect of the trunk. The change in femur angle must be due to other factors. As there is no difference in stride length between the two conditions, the effect of load is the most likely explanation. A significant increase in maximum femur angle with added load may be another factor contributing to the absorption of impact forces, increasing as knee flexion increases.

\subsubsection{Upper body}

Forward lean of the trunk has been the most commonly reported parameter in the biomechanical literature involving load carriage. An increase in forward lean has consistently been observed as increasing load is applied (Kinoshita 1985, Martin and Nelson 1986, Pascoe et al. 1997, Goh et al. 1998, Harman et al. 2000a, Filaire et al 2001). Craniovertebral angle has not received as much attention. It provides an estimation of the head and neck positioning on the upper trunk (Chansirinukor et al. 2001). Both angles were measured in this study.

The trunk angle was defined as the angle between the vertical and a line joining the virtual greater trochanter and C7 markers. As it was not possible to place markers elsewhere on the spine due to the backpack, movement about the hips may have influenced these data. The more negative this angle the greater the forward lean. What can be clearly seen in figure 5 is the effect that the addition of load has on trunk angle. In the control condition there is a more vertical, upright posture. The addition of webbing causes significant forward lean that is accentuated by addition of the backpack and finally the LAW.

These findings support previous research. Differing methods of measuring trunk angle have been used, but the same result has been produced. Load induces forward lean, necessary to rebalance the moments pivoted around the hips and to stabilise the body's centre of mass (Gordon et al. 1983, Kinoshita 1985, Martin and Nelson 1986, Pascoe et al. 1997, Goh et al. 1998). A more upright posture is usually 
considered more efficient when carrying load (Harman et al. 1999) but it may inhibit forward advancement of the body with load on the back (Kinoshita 1985).

Excess forward flexion would be resisted by eccentric contraction of the hamstrings and semispinalis muscles, placing them at risk of fatigue and injury when carrying heavy loads for sustained periods (Gordon et al. 1983). Carrying heavy loads may also be risk factor for lower back injury due to the increased stresses placed upon the back muscles and discs.

Stresses acting on different zones of the spinal column are also of importance when considering load carriage. Vacheron et al. (1999b) noted a decrease in intersegmental mobility in both lumbar and lower thoracic regions of the spine whilst carrying 22.5kg. Compensation for this increased the ROM in the cervical region, suggesting enhanced head/neck movements. These matters must be taken into consideration when examining the trunk as a whole, as in this study, and also the implications of these restrictions for the incidence of back pain.

Occupational or cultural requirements result in loads being carried on the head (African tribes), stabilized around the forehead (Sherpas), a yoke across the shoulders or, as here, in a backpack. The closer a load is to the body's mid-line (i.e. centre of mass), the smaller the change in posture (Kinoshita 1985, Harman et al. 1994), although even very light loads (3-10\% BW) can cause an increase in forward lean (Grimmer et al. 2002). Therefore, carrying loads on the head might be considered advantageous, especially as head carriage is physiologically beneficial (Soule and Goldman 1969, Datta and Ramanathan 1971). Set against this benefit, stresses on the small muscles of the neck increase as do lateral moments when traversing uneven terrain.

Another key measure of an individual's posture involves examination of head position relative to the upper trunk. Many recent studies concerning the effect of loads have not included this, although it was reported from a static examination of 160 individuals (Raine and Twomey 1997) and from a study of school children carrying loaded backpacks (Chansirinukor et al. 2001). In the latter, backpack loads of $15 \%$ BW caused an increased forward position of the head. Using loads up to $66 \% \mathrm{BW}$ (LAW condition), this finding was confirmed here, the craniovertebral angle decreasing with load. The data in figure 5 indicate little, if any, change in the head-totrunk line with load, the decreased craniovertebral angle resulting from the increased forward lean. Therefore the moment created by the head about the neck must have 
increased with load, forming a counterbalancing unit with the trunk. This unit thereby provides dynamic balance to stabilize the body. But, these greater moments imply increased stress on the neck muscles. The resulting strain has been associated with musculoskeletal dysfunction, head and neck aches and craniofacial and shoulder pain (Raine and Twomey 1997).

\section{Conclusion}

Load carriage is a military necessity. It needs to be as efficient and injury-free as possible. The main biomechanical effects of military load carriage include: increased ROM of the knee, increased forward lean and increased moments created by the head acting with the trunk to counterbalance the load. These changes necessitate increased muscular forces, perhaps exacerbating injury potential. Minimizing these biomechanical changes seems a rational design goal for military LCS. The duration of load carriage used here was brief. Responses to added load may change with duration of carriage, either through a process of physiological optimization, or more likely as a result of increasing fatigue.

\section{Acknowledgements}

The work described in this paper was fully supported by a grant from the Ministry of Defence, UK.

\section{References}

BHAMBHANI, Y. BUCKLEY S. AND MAIKALA R. 1997. Physiological and biomechanical responses during treadmill walking with graded loads. European Journal of Applied Physiology 76, 544-551.

BLOOM, D. AND WOODHULL-MCNEAL A. P. 1987. Postural adjustments while standing with two types of loaded backpack. Ergonomics 30, 1425-1430. 
CHANSIRINUKOR, W. WILSON D. GRIMMER K. AND DANSIE B. 2001. Effects of backpacks on students: Measurements of cervical and shoulder posture. Australian Journal of Physiotherapy 47, 110-116.

CHARTERIS, J. 1998. Comparison of the effects of backpack loading and of walking speed on foot-floor contact patterns. Ergonomics 41, 1792-1809.

CHOW, D.H.K., KWOK, M.L.Y., AU-YANG, A.C.K., HOLMES, A.D., CHENG, J.C.Y., YAO, F.Y.D. AND WONG, M.S. (2005) The effect of backpack loads on the gait of normal adolescent girls. Ergonomics, 15, 642-656.

COOK, T. M. AND NEUMANN D. A. 1987. The effects of load placement on the EMG activity of the low back muscles during load carrying by men and women. Ergonomics 30, 1413-1423.

DATTA, S. R. AND RAMANATHAN N. L. 1971. Ergonomic comparison of seven modes of carrying loads on the horizontal plane. Ergonomics 14, 269-278.

FILAIRE, M. VACHERON J.-J. VANNEUVILLE G. POURMARAT G. GARCIER J.-M. HAROUNA Y. GUILLOT M. TERVER S. TOUMI H. AND THIERRY C. 2001. Influence of the mode of load carriage on the static posture of the pelvic girdle and the thoracic and lumber spine in vivo. Surgical Radiologic Anatomy 23, 27-31.

GHORI, G. M. U. AND LUCKWILL R. G. 1985. Responses of the lower limb to load carrying in walking man. European Journal of Applied Physiology 54, 145-150.

GOH, J. H. THAMBYAH A. AND BOSE K. 1998. Effects of varying backpack loads on peak forces in the lumbosacral spine during walking. Clinical Biomechanics 13, S23-S31.

GORDON, M. J. GOSLIN B. R. GRAHAM T. AND HOARE J. 1983. Comparison between load carriage and graded walking on a treadmill. Ergonomics 26, 289-298.

GRIMMER, K. DANSIE B. MILANESE S. PIRUNSAN U. AND TROTT P. 2002. Adolescent standing postural response to backpack loads: a randomised controlled experimental study. Biomed Central Musculoskeletal Disorders 3, art. No. 10.

HAISMAN, M.F. (1988) Determinants of load carrying ability. Applied Ergonomics, 19, 111-121. 
HARMAN, E. FRYKMAN P. KNAPIK J. AND HAN K.-H. 1994. Backpack vs. front-back pack: Differential effects of load on walking posture. Medicine and Science in Sports and Exercise 26, S140.

HARMAN, E. FRYKMAN P. PANDORF C. THARION W. MELLO R. OBUSEK J. AND KIRK J. 1999. Physiological, biomechanical and maximal performance comparisons of soldiers carrying loads using U.S. Marine Corps modular lightweight load-carrying equipment (MOLLE), and U.S. Army Modular Load System (MLS) prototypes. Report No. 99-4. Natick, MA: U.S. Army Research Institute of Environmental Medicine.

HARMAN, E. HAN K.-H. FRYKMAN P. JOHNSON M. RUSSELL F. AND ROSENSTEIN M. 1992. The effects of gait timing, kinetics, and muscle activity of various loads carried on the back. Medicine and Science in Sports and Exercise 24, S129.

HARMAN, E. HAN K.-H. FRYKMAN P. AND PANDORF C. 2000(a). The effects of backpack weight on the biomechanics of load carriage. Report No. 00-14. Natick, MA: U.S. Army Research Institute of Environmental Medicine.

HARMAN, E. HAN K.-H. FRYKMAN P. AND PANDORF C. 2000(b). The effects of walking speed on the biomechanics of backpack load carriage. Report No. 00-20. Natick, MA: U.S. Army Research Institute of Environmental Medicine. HARMAN, E. OBUSEK J. P. FRYKMAN P. PALMER C. J. BILLS R. AND KIRK J. 1997. Backpacking energy cost and physical performance: Internal vs. external frame, belt vs. no belt. Medicine and Science in Sports and Exercise 29, S205.

HOLEWIJN, M. AND LOTENS W. A. 1992. The influence of backpack design on physical performance. Ergonomics 35, 149-157.

HONG, Y. AND CHEUNG C.-K. 2003. Gait and posture responses to backpack load during level walking in children. Gait and Posture 17, 28-33.

JOHNSON, R. F. KNAPIK J. J. AND MERULLO D. J. 1995. Symptoms during load carrying: Effects of mass and load distribution during a $20 \mathrm{~km}$ road march. Perceptual and Motor Skills 81, 331-338.

KADABA, M. P. RAMAKRISHNAN H. K. WOOTTEN M. E. GAINEY J. GORTON G. AND COCHRAN G. V. B. 1989. Repeatability of kinematic, kinetic and electromyographic data in normal adult gait. Journal of Orthopaedic Research 7, 849-860. 
KINOSHITA, H. 1985. Effects of different loads and carrying systems on selected biomechanical parameters describing walking gait. Ergonomics 28, 13471362.

KIRK, J. AND SCHNEIDER D. A. 1992. Physiological and perceptual responses to load-carrying in female subjects using internal and external frame backpacks. Ergonomics 35, 445-455.

KNAPIK, J. ANG P. MEISELMAN H. JOHNSON W. KIRK J. BENSEL C. AND HANLON W. 1997. Soldier performance and strenuous road marching: Influence of load mass and load distribution. Military Medicine 162, 62-67.

KNAPIK, J. HARMAN E. AND REYNOLDS K. 1996. Load carriage using packs: A review of physiological, biomechanical and medical aspects. Applied Ergonomics 27, 207-216.

KNAPIK, J. STAAB J. BAHRKE M. REYNOLDS K. VOGEL J. AND O'CONNOR J. 1991. Soldier performance and mood states following a strenuous road march. Military Medicine 156, 197-200.

LAFIANDRA, M. WAGENAAR R. C. HOLT K. G. AND OBUSEK J. P. 2003. How do load carriage and walking speed influence trunk co-ordination and stride parameters. Journal of Biomechanics 36, 87-95.

LLOYD, R. AND COOKE C. B. 2000a. The oxygen consumption associated with unloaded walking and load carriage using two different backpack designs. European Journal of Applied Physiology 81, 486-492.

LLOYD, R. AND COOKE C. B. 2000b. Kinetic changes associated with load carriage using two rucksack designs. Ergonomics 43, 1331-1341.

MARTIN, P. E. AND NELSON R. C. 1985. The effect of carried loads on the combative movement performance of men and women. Military Medicine 150, 357-362.

MARTIN, P. E. AND NELSON R. C. 1986. The effect of carried loads on the walking patterns of men and women. Ergonomics 29, 1191-1202.

MERATI, G. NEGRINI S. SARCHI P. MAURO F. AND VEICSTEINAS A. 2001. Cardio-respiratory adjustments and costs of locomotion in school children during backpack walking (the Italian backpack study). European Journal of Applied Physiology 85, 41-48. 
PASCOE, D. D. PASCOE D. E. WANG Y. T. SHIM D.-M. AND KIM C. K. 1997. Influence of carrying book bags on gait cycle and posture of youths. Ergonomics 40, 631-641.

QUESADA, P. M. MENGELKOCH L. J. HALE R. C. AND SIMON S. R. 2000. Biomechanical and metabolic effects of varying backpack loading on simulated marching. Ergonomics 43, 293-309.

RAINE, S. AND TWOMEY L. T. 1997. Head and shoulder posture variations in 160 asymptomatic women and men. Archives of Physical Medicine and Rehabilitation 78, 1215-1223.

SOULE, R. G. AND GOLDMAN R. F. 1969. Energy cost of loads carried on the head, hands, or feet. Journal of Applied Physiology 27, 687-690.

TILBURY-DAVIS, D. C. AND HOOPER R. H. 1999. The kinetic and kinematic effects of increasing load carriage upon the lower limb. Human Movement Science 18, 693-700.

VACHERON, J. J. POURMARAT G. CHANDEZON R. AND VANNEUVILLE G. 1999a. The effect of loads carried on the shoulder. Military Medicine 164, 597-599.

VACHERON, J. J. POURMARAT G. CHANDEZON R. AND VANNEUVILLE G. 1999b. Changes of contour of the spine caused by load carrying. Surgical Radiologic Anatomy 21, 109-113.

WANG, Y. T. PASCOE D. D. AND WEIMAR W. 2001. Evaluation of book backpack load during walking. Ergonomics 44, 858-869.

WHITTFIELD, J. K. LEGG S. J. AND HEDDERLEY D. I. 2001. The weight and use of schoolbags in New Zealand secondary schools. Ergonomics 44, 819-824. 
Table 1: Descriptive statistics of gait parameters (mean \pm SD)

\begin{tabular}{|l|l|l|l|l|}
\hline & Control & Webbing & Backpack & LAW \\
\hline Stride length (m) & $1.52 \pm 0.09$ & $1.60 \pm 0.11$ & $1.57 \pm 0.10$ & $1.55 \pm 0.09$ \\
\hline $\begin{array}{l}\text { Stride frequency } \\
\text { (strides/min) }\end{array}$ & $56.02 \pm 3.14$ & $58.37 \pm 3.61$ & $57.46 \pm 4.31$ & $57.03 \pm 3.56$ \\
\hline Stance time (seconds) & $0.60 \pm 0.04$ & $0.58 \pm 0.04$ & $0.60 \pm 0.06$ & $0.62 \pm 0.05$ \\
\hline Speed (m/s) & $1.42 \pm 0.11$ & $1.56 \pm 0.16$ & $1.50 \pm 0.15$ & $1.47 \pm 0.12$ \\
\hline
\end{tabular}


Figure 1: Testing conditions of experiment

Figure 2: Angular measurements

Figure 3: Mean ankle, knee and femur angles ( $\pm 95 \%$ confidence intervals) as a percentage of stance phase over all four testing conditions. Heel strike at $0 \%$ stance phase and toe off at $100 \%$ stance phase (dashed line).

Figure 4: Range of motion of the knee (Panel 4a) and the femur (Panel 4b) for the 4 loaded conditions.

* = significance at $p<0.005$ compared to control condition

\# = significance at $p<0.001$ compared to all conditions

Figure 5: Mean trunk and craniovertebral angles ( $\pm 95 \%$ confidence intervals) as a percentage of stance phase over all four testing conditions. Heel strike indicated at $0 \%$ stance phase and toe off at $100 \%$ (dashed line). Lower values indicate a greater forward lean (trunk) or a more forward head position (craniovertebral).

** = significance at $p<0.005$ compared to all conditions

$+=$ significance at $p<0.001$ compared to control condition 